\title{
Ketamine Effects on Eye Movements
}

\author{
Martin A. Weiler, M.D., Gunvant K. Thaker, M.D., Adrienne C. Lahti, M.D., \\ and Carol A. Tamminga, M.D.
}

In order to determine if the N-methyl-D-aspartate antagonist ketamine would reproduce eye movement dysfunction in schizophrenia, we studied 12 normal control subjects with low dose $(0.1 \mathrm{mg} / \mathrm{kg})$ bolus injection of ketamine in a double-blind placebo-controlled study. Oculomotor measures were obtained during smooth pursuit that included closed loop gain and measures of gain during masking conditions. Measures during initiation of smooth pursuit included latency, open loop acceleration and velocity. Ketamine disrupted closed loop gain and open loop acceleration but not measures during the masking conditions. The ketamine partly reproduced some abnormalities seen in schizophrenia but not measures that may be more specifically linked to familial abnormalities found in family members of subjects with schizophrenia.

[Neuropsychopharmacology 23:645-653, 2000] (C) 2000 American College of Neuropsychopharmacology. Published by Elsevier Science Inc.
KEY WORDS: NMDA; Ketamine; Smooth pursuit eye movements; Schizophrenia

This study sought to determine the effect of ketamine on eye movements to test the potential of ketamine as a human model for psychosis and assess the effect of ketamine on a measure of working memory. Ketamine is a non-competitive antagonist of $\mathrm{N}$-methyl-D-aspartate (NMDA) receptors and is in current medical use as a dissociative anesthetic.

Agents that block the NMDA receptors, especially phencyclidine in animals and its congener ketamine in humans have been of interest to researchers seeking a pharmacologic model for schizophrenia over several decades (Luby et al. 1959; Javitt and Zukin 1991; Tamminga et al. 1995). Recent studies of ketamine in normal volunteers suggests ketamine reproduces several positive and possibly negative symptoms seen in schizophrenia and simulates cognitive dysfunctions often

From the Maryland Psychiatric Research Center, University of Maryland at Baltimore, Baltimore, MD.

Address correspondence to: Martin A. Weiler, M.D., Maryland Psychiatric Research Center, P.O. Box 21247, Baltimore, MD 21228.

Received 24 December 1999; revised 9 May 2000; accepted 17 May 2000 seen in schizophrenia (Ghoneim et al. 1994; Krystal et al. 1994; Malhotra et al. 1996; LaPorte et al. 1996; Newcomer et al. 1998). In a study of persons with schizophrenia, Lahti et al. (1995b) reported that ketamine briefly exacerbated specific symptoms experienced during prior episodes of psychosis. These were accompanied by changes in limbic cerebral blood flow. These and other studies raised the question of whether ketamine's effect on smooth pursuit eye movement would mimic abnormalities that are frequently observed in schizophrenia, and/or exacerbate abnormalities already present in schizophrenic volunteers.

Eye tracking dysfunction (ETD) in schizophrenia was first reported in 1908 by Diefendorf \& Dodge (Diefendorf 1908) and has been replicated numerous times since physiologic recording of the phenomena by Holzman et al. (1973). ETD is stable during changes in clinical state, is unimproved by antipsychotic treatment, and is observed in unaffected as well as schizophrenia spectrum affected family members (Levy et al. 1993). These findings suggest that ETD has properties of a genetic trait marker for schizophrenia.

Generally, previous studies in schizophrenia have used measures of smooth pursuit such as closed-loop gain, which examine the final output of a highly complex and distributed system. However, it was of interest 
to examine the effects of ketamine on the individual components of the smooth pursuit system in order to identify specifically individual ocular motor processes and the underlying neural circuitry affected by the drug. The ocular motor system is unique in that sustained smooth pursuit eye movements are not generated in the absence of motion information. During the initial phase of smooth pursuit, i.e., pursuit initiation, the motion information is provided by a slippage of the image of the target of interest on the retina (henceforth called retinal motion signals). Measures such as eye velocity and acceleration during the initiation examine ability to process retinal motion information and integrate this into an appropriate smooth pursuit motor response. Data from only the first $100 \mathrm{msec}$ of initiation are used for these purposes to assure that response is not modified based on the visual feedback. Such pursuit response, independent of the visual feedback, is called the open-loop response.

Once the image of a moving target is captured on the fovea and the eye velocity approximates the target velocity, there is only a minimum slippage of the target image on the retina. Smooth pursuit during this so called maintenance phase is mostly driven by extraretinal motion signals with corrections based on the visual feedback (i.e., retinal error) (van den Berg 1988; Barnes and Asselman 1992). Such pursuit response, which also integrates retinal error information obtained through visual feedback, is called closed-loop response. The sources of the extraretinal motion signals include a copy of the motor command (so-called efference copy) and an internal representation of the retinal slip velocity. The measures obtained under the closed-loop condition evaluate the final output of the smooth pursuit system and are not informative about the individual component ocular motor processes. Thus, deficits in processing retinal motion signals, maintaining extraretinal motion information, integrating these into a motor command, and/or generating adequate smooth pursuit motor output can affect the closed-loop pursuit.

Recent studies have examined smooth pursuit responses to only extraretinal motion signals under experimental conditions in which there is a brief target extinction and reappearance at the appropriate location on the trajectory. Neurophysiological studies in monkey suggest that neurons in the medial superior temporal (MST) region continue to keep the motion information online after target extinction (Newsome et al. 1988; Boussaoud et al. 1990). This is dependent on the smooth pursuit eye movements and thus thought to encode eye velocity or the efference copy (Newsome et al. 1988; Boussaoud et al. 1990). In contrast to the MST region, posterior parietal cortex in monkey encodes previously presented retinal motion information in the absence of eye movements (Ferrera et al. 1994; Assad and Maunsell 1995). Studies indicate that patients with schizo- phrenia and their non-psychotic relatives have poor smooth pursuit response to only extraretinal motion signals (Thaker et al. 1998, 1999).

The current study examined effects of ketamine on the closed-loop pursuit, pursuit response to only retinal motion signals during initiation, and responses to only extraretinal motion. The latter was of particular interest for examining the effects of ketamine and other NMDA antagonists because the concept of extraretinal motion parallels the working memory construct. Aside from its relevance to schizophrenia, the effects of ketamine on eye movements can help to clarify the role of NMDAsensitive glutamatergic transmission plays in eye movements and aspects of working memory. The effects of ketamine on working memory components of our tasks would help to clarify how ketamine affects frontal lobe function, an action already implicated in several neurochemical and imaging studies (Verma and Moghaddam 1996; Javitt et al. 1996; Moghaddam et al. 1997; Lahti et al. 1995a; Breier et al. 1997; Krystal et al. 1994).

A previous study has already assessed eye tracking during ketamine infusion using a prolonged, escalating dosage infusion (Radant et al. 1998). The results of that study showed that ketamine effects on eye movement in normal volunteers are similar in some respects to the eye movement abnormalities in schizophrenia in showing disruption in gain, and increased catch-up saccade frequency early in the infusion before significant nystagmus was noted later in the infusion and at higher doses. In this study we have used a bolus infusion of ketamine at a low dose $(0.1 \mathrm{mg} / \mathrm{kg})$ that does not produce nystagmus.

\section{METHODS}

\section{Volunteers}

Subjects were recruited from the community by newspaper advertisement and screened in a telephone interview. All subjects gave written informed consent and were paid $\$ 10$ per hour for their time. Subjects were evaluated with the Structured Clinical Interview for DSM III-R (SCID-NP) (Spitzer et al. 1990), Structured Interview for DSMIII-R Personality Disorders (SIDP-R) (Pfohl et al. 1989), Chapman Scales for Perceptual Aberration (Chapman and Chapman 1984), medical history, physical exam, and blood and urine laboratory studies including drug screen. Subjects were excluded for current or lifetime Axis I or II disorders, medical conditions that would render ketamine infusions unsafe and any neurological disorders. Subjects with elevated Chapman scores were excluded. Current or lifetime abuse of any substances as defined by DSMIII-R criteria or any substances found in the urine drug screen would also exclude subjects. Subjects were on no medication other 
than vitamins. Procedures were approved by the University of Maryland, Baltimore Internal Review Board.

Subjects included 10 males and two females, mean age 34.0 with mean socioeconomic status 2.7. All subjects had prior exposure to ketamine in bolus infusion in a laboratory setting that did not involve eye tracking tasks.

\section{Laboratory Procedures}

Eye Tracking Procedures. Targets were presented on a CRT screen 28" from the subjects eyes. After stepping to the left or right of center, the target (a cross inside a $.25 \times .25$ degree box) began moving from the center across the screen at 9.4 or 18.7 degrees per second of constant target speed over a 24 degree span of the $15^{\prime \prime}$ monitor. After several cycles of motion, the target was unpredictably blanked out (masked) for $500 \mathrm{msec}$, after which the target re-appeared at the same position and velocity as cycles without a mask. The subjects were instructed to ". . f follow the target as it moves. Occasionally the target will become invisible for very brief periods. During these periods, the target will keep on moving, so continue moving your eyes to follow the invisible but moving target."

In half the trials, the mask occurred at the beginning of the ramp (Figure 1) requiring the subject to change directions during the mask. In the other half of the trials, the mask occurred in the middle of the ramp (Figure 2) requiring the subject to continue in the same direction. One block of trials consisted of 12 presentations lasting 3.5 minutes. Half of the trials used 9.4 and the other half 18.7 degree/second target speeds.

Ketamine Infusions. On each of two study days, subjects had an intravenous catheter placed with a drip of normal saline to keep open the vein. Subject's pulse and oxygen saturation were continuously monitored. After two baseline eye tracking blocks, subjects were injected with ketamine $0.1 \mathrm{mg} / \mathrm{kg}$ or a placebo bolus injection over 1 minute. Subjects were then tested on two eye tracking blocks lasting a total of 10 minutes. Subjects were then assessed for symptoms and recordings of blood pressure were made. Half of the subjects received ketamine on the first study day and placebo on the second in

\section{A trial with mask at the beginning of a half-cycle}

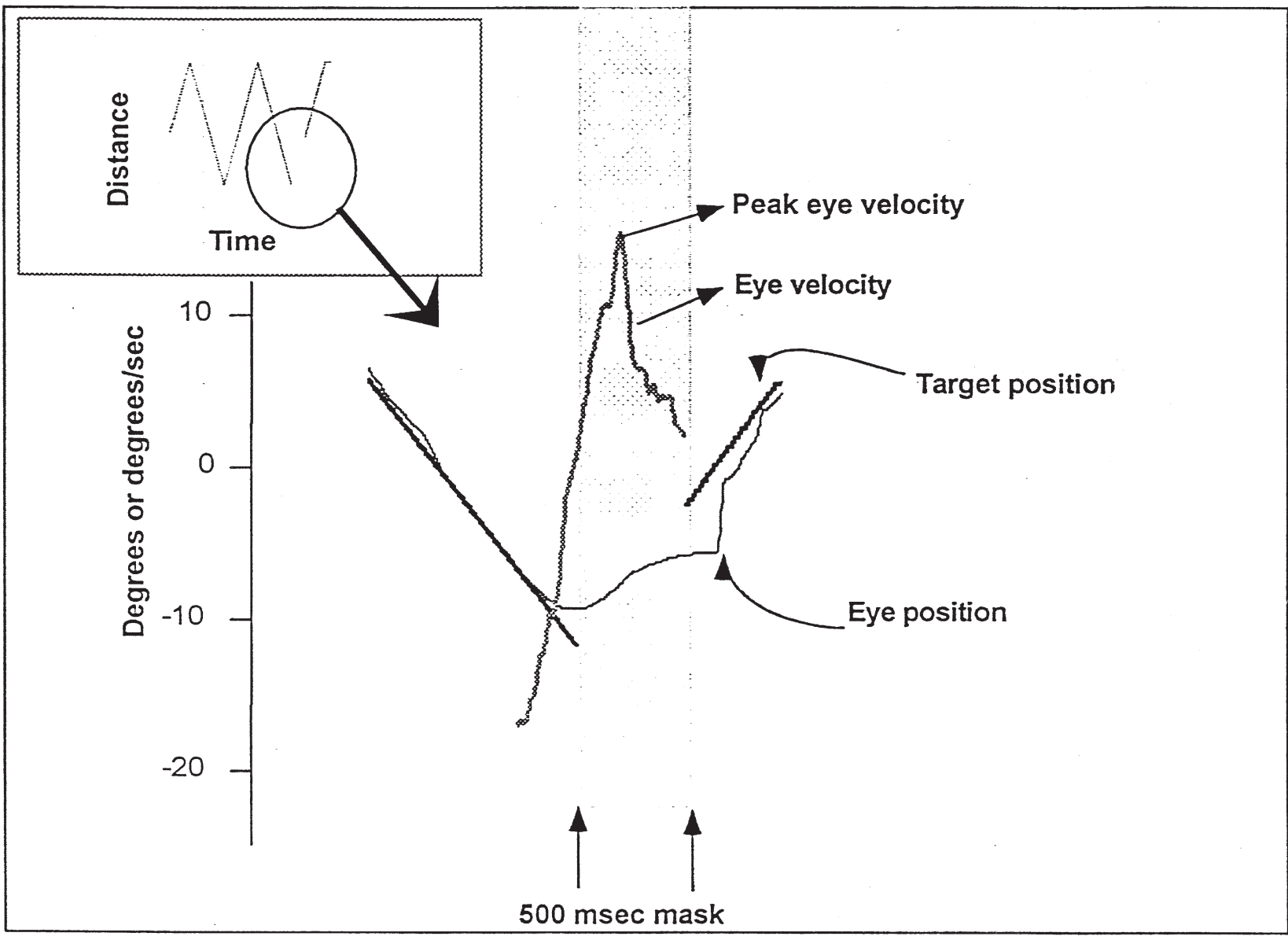

Figure 1. The upper left panel displays the target velocity of a single ramp-mask-ramp trial. The expanded area shows an example of measures during a mask at the beginning of the ramp with eye velocity and eye position graphed. 


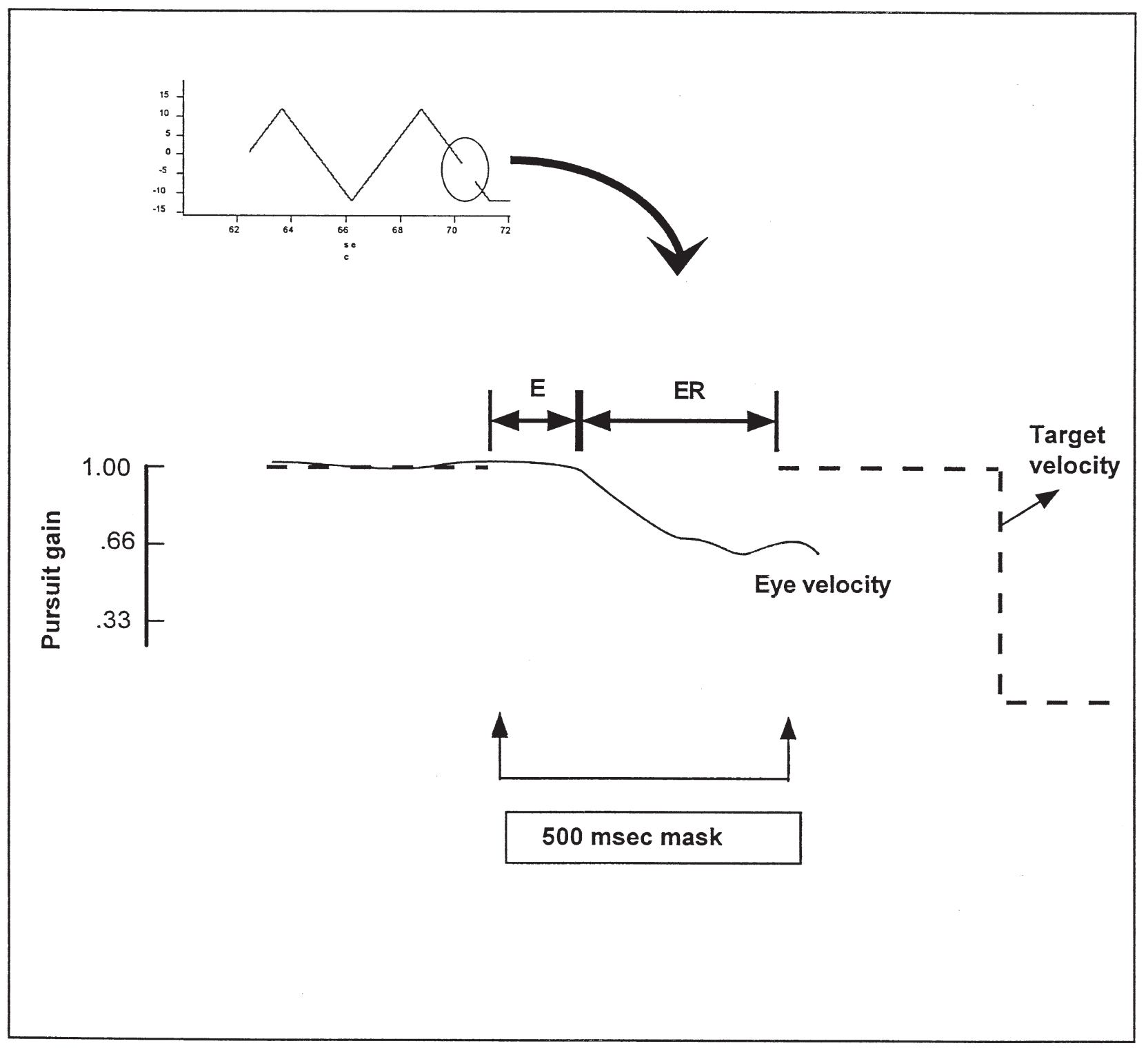

Figure 2. The upper left panel displays the target velocity of a single ramp-mask-ramp trial with the mask in the middle of the ramp. The expanded area shows the eye velocity continuing through E and then drops during ER. The residual predictive pursuit gain is the ratio of eye velocity during ER to the target velocity before the mask.

a double-blind fashion. The rest of the subjects had placebo on the first study day and ketamine the second.

The dose level of $0.1 \mathrm{mg} / \mathrm{kg}$ was chosen based on a previous dose ranging study. At this dose, mild analgesia is produced with very mild visual and bodily distortions, but no psychotic symptoms, no blood pressures or pulse changes and no optical nystagmus. The peak effect of the ketamine is approximately 3 minutes after injection and the effect lasts approximately 8 minutes.

\section{Oculomotor Data Acquisition}

Eye movement data were collected by infrared oculometry (sampling rate of $333 \mathrm{~Hz}$ with a time constraint of 4 milliseconds), filtered with $75 \mathrm{~Hz}$ low-pass filter, and digitized with a 16 bit $\mathrm{A}$ to $\mathrm{D}$ converter. Calibration and scoring were done with waveform analysis software that allowed semi-automated analysis and active monitoring by a trained scorer.

\section{Eye Movement Measures}

Eye blinks and saccades were removed from the records. Measures of performance were obtained for closed loop pursuit gain, velocity during the mask condition and during pursuit initiation.

1. Closed loop pursuit gain was measured from the ramp preceding the mask. Smooth pursuit eye veloc- 
ity values were divided by target velocity values for each $3 \mathrm{msec}$ section and averaged for each trial.

2. Three sets of measures of performance during the mask were obtained: 1) Peak gain during masks occurring at the beginning of the ramp (eye velocity/ predicted target velocity). In such trials, subjects changed direction of pursuit and initiated pursuit in the anticipated direction (Figure 1). Latency: The timing of the change of direction of the eye in relation to the expected direction change of the target was measured. This change of direction latency was evaluated as an absolute value; 2) Mean gain during 101$400 \mathrm{msec}$ interval of the mask occurring during a ramp (eye velocity/predicted target velocity; Figure 2); and 3) Residual predictive gain for trials with the mask occurring during the ramp. In such trials, subjects followed the target trajectory at the same velocity as before the mask for about 130 to $190 \mathrm{msec}$, presumably still partly responding to retinal motion information available just prior to the onset of the mask period. After this initial period, there was a 35$50 \%$ drop in the eye velocity and then the velocity stabilized at this new level until the end of the mask. This residual velocity is thought to reflect pursuit responses based on only extraretinal signals (Becker and Fuchs 1985) and was measured to obtain residual predictive gain (Thaker et al. 1998).

3. Three measures of performance during initiation of each ramp was obtained using methods described elsewhere (Ross et al. 1996) (Figure 3): 1) Latency to onset of smooth pursuit; 2) Open loop acceleration from the first $100 \mathrm{msec}$ of smooth pursuit, where no visual feedback is available to the oculomotor system; and 3) Open loop velocity during the first 100 msec after onset of smooth pursuit.

\section{Data Analysis}

Before final data analysis, dependent variables were plotted to insure the data corresponded to a normal distribution. Preliminary analysis was also performed for order effects (i.e., whether the subject received ketamine versus placebo first) and no differences were found. We also compared the 10 males to the two females and found no differences, so both sexes were combined for the final analysis. We also compared the two blocks of trials subsequent to ketamine injection for differences but none were found, thus allowing combining these blocks for subsequent analysis.

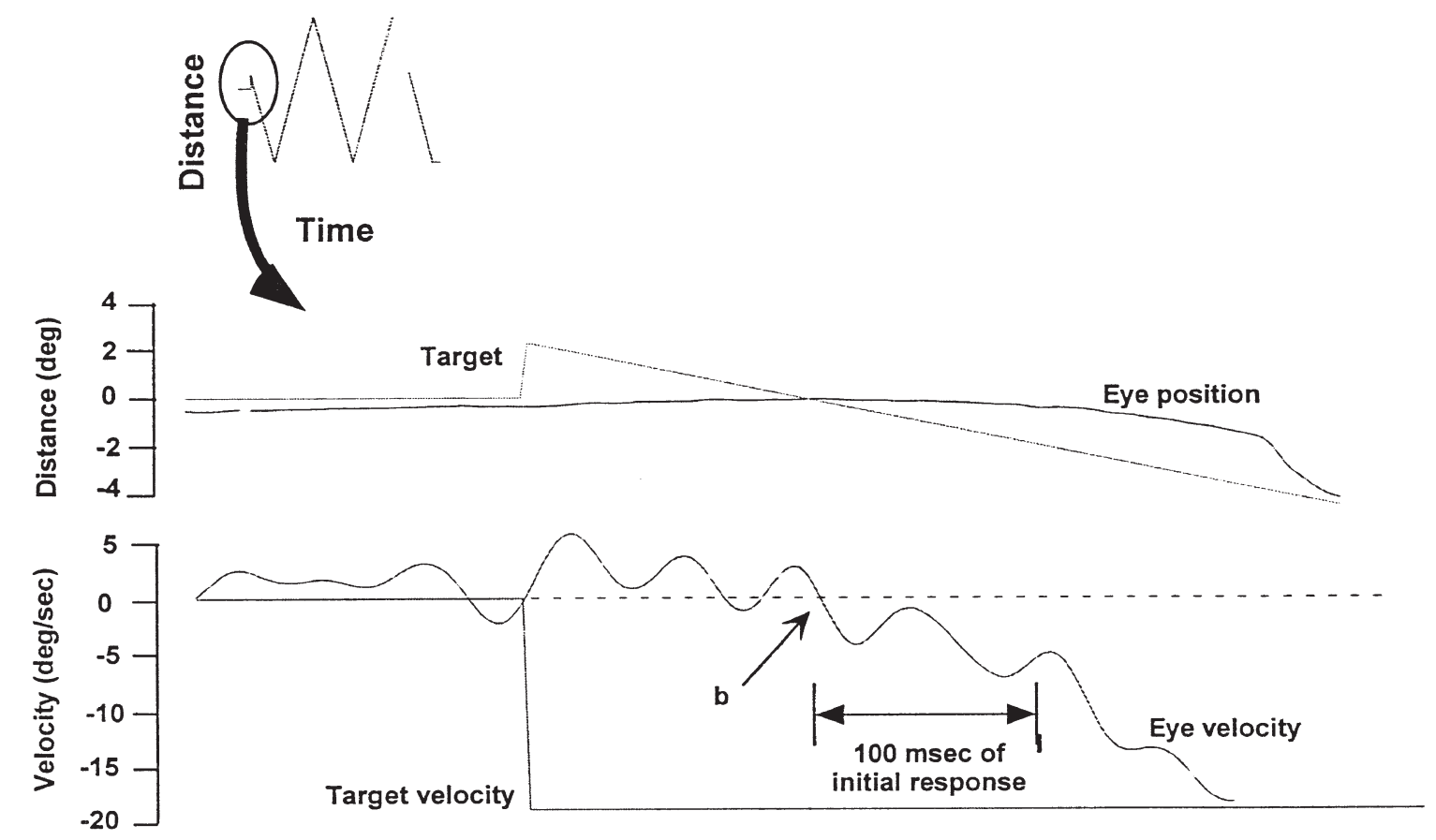

Figure 3. The middle panel shows initiation of eye movements at the beginning of a trial with eye velocity shown in the lower panel. Point $b$ shows the latency of eye movements from the target onset. Following $b$ for $100 \mathrm{msec}$ is the open loop acceleration and velocity of eye movements. 
For each subject, data were collapsed across trials to obtain mean values on the two baseline blocks and two blocks subsequent to placebo and ketamine injection. Repeated measures analysis of variance was performed using within-subject factors of phase (baseline vs. injection), drug (placebo vs. ketamine), and target velocity (9.4 vs. 18.7 degrees per second) on the dependent variables. For statistical significance, the $\alpha$ level was set at 0.05 . Post hoc comparisons used Tukey's honestly significant difference tests. Results are presented as mean \pm standard deviation.

\section{RESULTS}

The means, standard deviations and analysis of variance values for the measures are presented in Table 1.

1. Ketamine significantly decreased closed loop gain as determined by phase by drug interactions $\left(\mathrm{F}_{1,11}=\right.$ 13.51, $p<.004)$. Post hoc comparison suggested no effect of baseline $(0.873 \pm 0.088)$ versus placebo injection $(0.849 \pm 0.097)$ but a significant change with ketamine infusion $(0.845 \pm 0.082$ versus $0.715 \pm$ 0.116). Next the effects of ketamine on individual components were evaluated.

2. Eye acceleration during initiation was significantly decreased with ketamine but not with placebo as suggested by drug by phase interaction $\left(\mathrm{F}_{1,11}=5.66\right.$, $p<.037)$. Probing the interaction showed no effect of placebo and significant effect of ketamine on eye acceleration $\left(\mathrm{F}_{1,11}=7.52, p<.02\right)$. This suggests impairment in processing retinal motion information and generating a motor response. Measures of open loop pursuit latency and velocity were not significantly affected by ketamine.
3. There was no effect of ketamine on predictive pursuit in response to extraretinal motion information. The peak gain for masks at the beginning of the $\operatorname{ramp}\left(\mathrm{F}_{1,11}=.01, p=.941\right)$ and changes in direction latency were not significantly affected by ketamine.

4. Ketamine decreased mean mask gain. Significant effects of ketamine as determined by phase by drug interactions were noted for mean mask gain $\left(\mathrm{F}_{1,11}=\right.$ $9.48, p<.011$ ) for masks during the ramp. There was no significant effect of placebo challenge but ketamine significantly worsened mean gain during the mask $\left(\mathrm{F}_{1,11}=10.046, p<.009\right)$. The reduced mean mask gain with ketamine, however, may be secondary to the low pre-mask closed-loop gain and/or reflect the effects of retinal motion signals in the first 130 to $190 \mathrm{msec}$ of the mask. Therefore, we examined the effects of the drug on residual predictive gain. Ketamine had no significant effect on the residual predictive gain $\left(\mathrm{F}_{1,11}=2.70, p=.128\right)$. This suggests the decreased mean mask gain was probably secondary to the decreased closed-loop gain (No. 1 above).

5. Total BPRS scores showed a small increase from baseline $(18.36 \pm 0.50)$ to ketamine infusion (20 \pm 2.46), reflecting mild increases in withdrawal and thought disorder subscales.

\section{DISCUSSION}

The purpose of this investigation was to determine if ketamine in low doses would produce abnormalities in the eye movements of normal volunteers that are observed in subjects with schizophrenia. Ketamine appears to produce some abnormalities in eye movements

Table 1. Means, Standard Deviations and Analysis of Variance Results for Eye Movement Measures

\begin{tabular}{|c|c|c|c|c|c|c|}
\hline & \multirow{2}{*}{$\begin{array}{c}\text { Target } \\
\text { Velocity }\end{array}$} & \multicolumn{2}{|c|}{ Placebo Day } & \multicolumn{2}{|c|}{ Ketamine Day } & \multirow{2}{*}{$\begin{array}{c}\text { F,P df for } \\
\text { Phase by Drug }\end{array}$} \\
\hline & & Baseline & Infusion & Baseline & Infusion & \\
\hline \multicolumn{7}{|l|}{ Closed Loop Condition } \\
\hline Pursuit Gain 1 & $\begin{array}{r}9.4 \\
18.7\end{array}$ & $\begin{array}{l}.859 \pm .088 \\
.887 \pm .089\end{array}$ & $\begin{array}{l}.895 \pm .091 \\
.803 \pm .102\end{array}$ & $\begin{array}{l}.882 \pm .087 \\
.810 \pm .078\end{array}$ & $\begin{array}{l}.769 \pm .130 \\
.663 \pm .102\end{array}$ & $13.51 .0041,11$ \\
\hline \multicolumn{7}{|l|}{ Mask During the Ramp } \\
\hline Mean Gain 2 & $\begin{array}{r}9.4 \\
18.7\end{array}$ & $\begin{array}{l}.617 \pm .173 \\
.611 \pm .114\end{array}$ & $\begin{array}{l}.692 \pm .156 \\
.642 \pm .154\end{array}$ & $\begin{array}{l}.649 \pm .117 \\
.670 \pm .171\end{array}$ & $\begin{array}{l}.506 \pm .194 \\
.503 \pm .183\end{array}$ & $9.48 .0111,11$ \\
\hline Residual Predictive Gain 3 & $\begin{array}{r}9.4 \\
18.7\end{array}$ & $\begin{array}{l}.503 \pm .119 \\
.454 \pm .100\end{array}$ & $\begin{array}{l}.524 \pm .172 \\
.468 \pm .102\end{array}$ & $\begin{array}{l}.564 \pm .111 \\
.428 \pm .076\end{array}$ & $\begin{array}{l}.482 \pm .089 \\
.409 \pm .126\end{array}$ & $2.70 .1281,11$ \\
\hline \multicolumn{7}{|l|}{ Mask at Beginning of Ramp } \\
\hline Peak Gain 4 & $\begin{array}{r}9.4 \\
18.7\end{array}$ & $\begin{array}{l}.717 \pm .237 \\
.596 \pm .131\end{array}$ & $\begin{array}{l}.754 \pm .247 \\
.560 \pm .186\end{array}$ & $\begin{array}{l}.616 \pm .189 \\
.582 \pm .171\end{array}$ & $\begin{array}{l}.673 \pm .218 \\
.535 \pm .163\end{array}$ & $.01 .9411,11$ \\
\hline \multicolumn{7}{|l|}{ Initiation Measures } \\
\hline Open Loop Acceleration 7 & $\begin{array}{r}9.4 \\
18.7\end{array}$ & $\begin{array}{r}59.42 \pm 25.8 \\
61.6 \pm 31.3\end{array}$ & $\begin{array}{l}65.6 \pm 21.2 \\
57.2 \pm 19.5\end{array}$ & $\begin{array}{l}61.3 \pm 17.7 \\
63.1 \pm 24.1\end{array}$ & $\begin{array}{l}43.5 \pm 14.3 \\
49.3 \pm 21.8\end{array}$ & $5.66 .0371,11$ \\
\hline Latency 5 & $\begin{array}{r}9.4 \\
18.7\end{array}$ & $\begin{array}{l}.127 \pm 0.24 \\
.119 \pm .016\end{array}$ & $\begin{array}{l}.131 \pm .025 \\
.129 \pm .029\end{array}$ & $\begin{array}{l}.161 \pm .118 \\
.131 \pm .042\end{array}$ & $\begin{array}{l}.140 \pm .026 \\
.135 \pm .040\end{array}$ & $.067 .8011,11$ \\
\hline Open Loop Velocity 6 & $\begin{array}{r}9.4 \\
18.7\end{array}$ & $\begin{array}{l}.362 \pm .185 \\
.152 \pm .079\end{array}$ & $\begin{array}{l}.371 \pm .153 \\
.169 \pm .083\end{array}$ & $\begin{array}{l}.340 \pm .125 \\
.167 \pm .064\end{array}$ & $\begin{array}{l}.302 \pm .127 \\
.155 \pm .074\end{array}$ & $.039 .8471,11$ \\
\hline
\end{tabular}


common to schizophrenia, but not all abnormalities. A traditional measure of smooth pursuit, closed loop gain showed a significant worsening during ketamine that resembles the smooth pursuit deficits seen in schizophrenia (Friedman et al. 1991). This result is similar to the findings of Radant et al. (1998). Ketamine also produced deficits in open loop acceleration that has been observed in schizophrenia (Clementz and McDowell 1994; Ross et al. 1996).

In terms of predictive pursuit, where eye movement measures are obtained during periods where the target was masked, the effect of ketamine is more complex. When the mask occurred during a ramp, mean mask gain was affected by the drug. However, this measure may be vulnerable to response based on retinal motion signals. In contrast, residual predictive gain, which is thought to be based on mainly extraretinal signals, was unaffected by ketamine. Similarly, ketamine did not disrupt the peak gain measure obtained from trials with masks at the beginning of the ramp. The latter two findings suggest that ketamine did not significantly disrupt the predictive component of the smooth pursuit function. In an earlier study comparing relatives of patients with schizophrenia and normal groups, measures of predictive pursuit were found to be impaired in relatives (Thaker et al. 1999). This measure, which is similar to working memory of target trajectory, of eye movement control is not similar between a ketamine infusion and schizophrenia.

Brain imaging studies with ketamine have been done in an attempt to delineate areas involved with its psychotomimetic effects. Breier and coworkers (1997) found increases in frontal areas and a small area of decrease in the cerebellum during a prolonged ketamine infusion and 18-F-fluorodeoxyglucose positron emission tomography (PET). We have reported anterior cingulate and central frontal increases and reduced hippocampus and primary visual cortex in subjects with schizophrenia during a $0.3 \mathrm{mg} / \mathrm{kg}$ bolus injection and $\mathrm{H}_{2}{ }^{15} \mathrm{O}$ rCBF PET study (Lahti et al. 1995a).

Our more recent PET, ketamine studies with larger numbers of normal controls confirm cingulate and frontal activations and showed a profound decrease in cerebellum (Lahti et al. 1997). Bolus injected ketamine may block the abundant $\mathrm{R} 2 \mathrm{C}$ subtype of NMDA receptors in the granule cell layer of the cerebellum. The ketamineinduced eye movement changes reported here may be best explained as mediated by the disruption of sensory-motor contributions within the cerebellum to eye movements. A study of Purkinje cell activity in the monkey posterior vermis during smooth pursuit suggested that the posterior vermis is involved in processing retinal image velocity and calculating target velocity in visual space based on the summation of current retinal slip velocity and internal representation of the eye velocity (Suzuki and Keller 1988). Thus, dysfunction in vermis would affect both the initiation response as well as closed-loop pursuit gain. Caution is indicated in this interpretation of ketamine on the cerebellum. Animal studies on the binding of ketamine suggest lower affinity in the cerebellum than in the hippocampus (Yoneda and Ogita 1991) and the forebrain (Porter and Greenamyre 1995). The cerebellum is rich in the NMDAR2C subunit whereas the NMDAR2A and NMDAR2B subunits are expressed more strongly in the cortex and hippocampus (Nakanishi 1992). Also, in a recent study of subjects with cerebellar degeneration, Moschner et al. (1999) found a significant increase in latency and decreased acceleration of eye movement initiation whereas we found only decreases in acceleration. These studies suggest other areas of the brain than the cerebellum may be responsible for ketamine effect.

A second reason to be cautious in interpreting our findings is that the dose of ketamine may have been too low to elicit effects on our memory related measures. Ketamine has been shown to cause impairment in several measures of attention and memory (Malhotra et al. 1996; LaPorte et al. 1996; Newcomer et al. 1998). The study by Newcomer and coworkers (1998) showed dose dependent decreases in verbal and nonverbal declarative memory but not visual spatial delayed response. Our results appear to agree with less impairment in memory related to the visual system. Our intent in using a low dose was to avoid nystagmus and insure the subject could cooperate fully with the testing. Higher doses of ketamine may have produced significant effects on more of our measures. A third reason for caution is that our sample size may be too small to detect smaller effects. The lack of effect on the working memory of target trajectory suggests intact frontal functioning at this dose level. If our interpretation of cerebellar dysfunction is correct, it may be that ketamine disrupts an essential timing or error correction function attributed to the cerebellum in many tasks (Ivry and Keele 1989; Jueptner et al. 1995).

The results of this study seem to fit with other work that implicates the cerebellar dysfunction in schizophrenia (Andreasen et al. 1998; Andreasen 1999; Martin and Albers 1995). Ketamine at this dose level appears to target our measures involving the cerebellum more than our measures that tap cortical functions. The ketamine model of schizophrenia appears not to disrupt the eye movements that have a genetic component.

\section{REFERENCES}

Andreasen NC (1999): A unitary model of schizophrenia. Arch Gen Psychiatry 56:781-787

Andreasen NC, Paradiso S, O'Leary DS (1998): Cognitive dysmetria as an integrative theory of schizophrenia: A dysfunction in cortical-cerebellar circuitry? Schizophr Bull 24:203-218 
Assad JA, Maunsell JH (1995): Neuronal correlates of inferred motion in primate posterior parietal cortex. Nature 373:518-521

Barnes GR, Asselman PT (1992): Pursuit of intermittently illuminated moving targets in the human. J Physiol 445:617-637

Becker W, Fuchs AF (1985): Prediction in the oculomotor system: Smooth pursuit during transient disappearance of a visual target. Exp Brain Res 57:562-575

Boussaoud D, Ungerleider LG, Desimone R (1990): Pathways for motion analysis: Cortical connections of the medial superior temporal and fundus of the superior temporal visual areas in the macaque. J Comp Neurol 296:462-495

Breier A, Malhotra AK, Pinals DA, Weisenfeld NI, Pickar D (1997): Association of ketamine-induced psychosis with focal activation of the prefrontal cortex in healthy volunteers. Am J Psychiatry 154:805-811

Chapman LJ, Chapman JP (1984): Psychosis proneness. In Alpert M (ed), Controversies in Schizophrenia: Changes and Constancies. New York, NY, Guilford Press, pp 157-174

Clementz BA, McDowell JE (1994): Smooth pursuit in schizophrenia: Abnormalities in open- and closed- loop responses. Psychophysiology 31:79-86

Diefendorf ARDR (1908): An experimental study of the ocular reactions of the insane from photographic records. Brain 31:451-489

Ferrera VP, Rudolph KK, Maunsell JH (1994): Responses of neurons in the partial and temporal visual pathways during a motion task. J Neurosci 14:6171-6186

Friedman L, Jesberger JA, Meltzer HY (1991): A model of smooth pursuit performance illustrates the relationship between gain, catch-up saccade rate and catch-up saccade amplitude in normal controls and patients with schizophrenia. Biol Psychiatry 30:537-556

Ghoneim MM, Chen P, El-Zahaby HM, Block RI (1994): Ketamine: Acquisition and retention of classically conditioned responses during treatment with large doses. Pharmacol Biochem Behav 49:1061-1066

Holzman PS, Proctor LR, Hughes DW (1973): Eye tracking patterns in schizophrenia. Science 181:179-181

Ivry RB, Keele SW (1989): Timing functions of the cerebellum. J Cogn Neurosci 1:136-152

Javitt DC, Doneshka P, Grochowski S, Ritter W, Jonides J, Smith EE, Koeppe RA, Awh E, Minoshima S, Mintun MA, Just MA, Carpenter PA, Huerta MF, Krubitzer LA, Kaas JH, Keating EG, Pierre A, Chopra S (1996): Impaired mismatch negativity generation reflects widespread dysfunction of working memory in schizophrenia. Arch Gen Psychiatry 76:637-641

Javitt DC, Zukin SR (1991): Recent advances in the phencyclidine model of schizophrenia. Am J Psychiatry 148: 1301-1308

Jueptner M, Rijntjes M, Weiller C, Faiss JH, Timmann D, Mueller SP, Diener HC (1995): Localization of a cerebellar timing process using PET. Neurology 45:1540-1545

Krystal JH, Karper LP, Seibyl JP, Freeman GK, Delaney R, Bremner D, Heninger GR, Bowers MB, Charney DS (1994): Subanesthetic effects of the noncompetitive
NMDA antagonist, ketamine, in humans: Psychotomimetic, perceptual, cognitive, and neuroendocrine responses. Arch Gen Psychiatry 51:199-214

Lahti AC, Holcomb HH, Medoff DR, Tamminga CA (1995a): Ketamine activates psychosis and alters limbic blood flow in schizophrenia. Neuroreport 6:869-872

Lahti AC, Holcomb HH, Weiler MA, Corey PK, Zhao M, Medoff D, Tamminga CA (1997): Effects of ketamine on behavior and rCBF in schizophrenic and normal individuals. Biological Psychiatry 41:165

Lahti AC, Koffel B, LaPorte DJ, Tamminga CA (1995b): Subanesthetic doses of ketamine stimulate psychosis in schizophrenia. Neuropsychopharmacology 13:9-19

LaPorte DJ, Lahti AC, Koffel B, Tamminga CA (1996): Absence of ketamine effects on memory and other cognitive functions in schizophrenic patients. J Psychiatric Res 30:321-330

Levy DL, Holzman PS, Matthysse S, Mendell NR (1993): Eye tracking dysfunction and schizophrenia: A critical perspective [published erratum appears in Schizophr Bull 1993;19(4):685]. Schizophr Bull 19:461-536

Luby ED, Cohen BD, Rosenbaum G, Gottlieb JS, Kelley R (1959): Study of a new schizophrenomimetic drug: Serenyl. Arch Neurol Psychiatry 71:363-369

Malhotra AK, Pinals DA, Weingartner H, Sirocco K, Missar CD, Pickar D, Breier A (1996): NMDA receptor function and human cognition: The effects of ketamine in healthy volunteers. Neuropsychopharmacology 14:301-307

Martin P, Albers M (1995): Cerebellum and schizophrenia: A selective review. Schizophrenia Bull 21:241-250

Moghaddam B, Adams B, Verma A, Daly D (1997): Activation of glutamatergic neurotransmission by ketamine: $\mathrm{A}$ novel step in the pathway from NMDA receptor blockade to dopaminergic and cognitive disruptions associated with the prefrontal cortex. J Neurosci 17:2921-2927

Moschner C, Crawford TJ, Heide W, Trillenberg P, Kompf D, Kennard C (1999): Deficits in smooth pursuit initiation in patients with degenerative cerebellar lesions. Brain 122:2147-2158

Nakanishi S (1992): Molecular diversity of glutamate receptors and implications for brain function. Science 258:597-603

Newcomer JW, Farber NB, Jevtovic-Todorovic V, Selke G, Melson AK, Hershey T, Craft S, Olney JW (1998): Ketamine-induced NMDA receptor hypofunction as a model of memory impairment and psychosis. Neuropsychopharmacology 20:106-118

Newsome WT, Wurtz RH, Komatsu H (1988): Relation of cortical areas MT and MST to pursuit eye movements. II. Differentiation of retinal from extraretinal inputs. J Neuophysiol 60:604-620

Pfohl B, Blum N, Zimmerman M, Stangl D (1989): Structured Interview for DSM-III-R Personality (SIDP-R). University of Iowa, Department of Psychiatry, Iowa City, Iowa

Porter RH, Greenamyre JT (1995): Regional variations in the pharmacology of NMDA receptor channel blockers: Implications for therapeutic potential. J Neurochem 64:614-623

Radant AD, Bowdle TA, Cowley DS, Kharasch ED, RoyByrne PP (1998): Does ketamine-mediated N-methyl- 
D-aspartate receptor antagonism cause schizophrenialike oculomotor abnormalities? Neuropsychopharmacology 19:434-444

Ross DE, Thaker GK, Buchanan RW, Lahti AC, Medoff D, Bartko JJ, Moran M, Hartley J (1996): Association of abnormal smooth pursuit eye movements with the deficit syndrome in schizophrenic patients. Am J Psychiatry 153:1158-1165

Spitzer RL, Williams JBW, Gibbon M, First MB (1990): Structured Clinical Interview for DSM III-R (SCID) PB. New York, NY, New York State Psychiatric Institute, Biometrics Research Department

Suzuki DA, Keller EL (1988): The role of the posterior vermis of monkey cerebellum in smooth-pursuit eye movement control. II. Target velocity-related Purkinje cell activity. J Neurophysiol 1:19-40

Tamminga CA, Holcomb HH, Gao XM, Lahti AC (1995): Glutamate pharmacology and the treatment of schizophrenia: Current status and future directions. Int Clin Psychopharmacol 3(Suppl 10):29-37
Thaker GK, Ross DE, Buchanan R, Adami H, Medoff D (1999): Smooth pursuit eye movements to extraretinal motion signals: Deficits in motion memory in schizophrenia. Psychiatry Res 88:209-219

Thaker GK, Ross DE, Cassady SL, Adami HM, LaPorte D, Medoff DR, Lahti A (1998): Smooth pursuit eye movements to extraretinal motion signals: Deficits in relatives of patients with schizophrenia. Arch Gen Psychiatry 55:830-836

van den Berg AV (1988): Human smooth pursuit during transient perturbations of predictable and unpredictable target movement. Exp Brain Res 72:95-108

Verma A, Moghaddam B (1996): NMDA receptor antagonists impair prefrontal cortex function as assessed via spatial delayed alternation performance in rats: Modulation by dopamine. J Neurosci 16:373-379

Yoneda Y, Ogita K (1991): Heterogeneity of the N-methyl$\mathrm{D}$-aspartate receptor ionophore complex in rat brain, as revealed by ligand binding techniques. J Pharmacol Exp Ther 259:86-96 